\title{
BALANCED SCORECARD. UMA PROPOSTA PARA A GESTÃO ESTRÁTEGICA DE UMA COOPERATIVA DE CRÉDITO RURAL
}

Data de submissão: 07/11/2014 Aceite: $26 / 05 / 2016$

Silvana Dalmutt Kruger ${ }^{1}$ Aline Simionato ${ }^{2}$ Cleunice Zanella ${ }^{3}$ Sérgio Murilo Petri ${ }^{4}$

\section{RESUMO}

Este estudo propõe um modelo para a gestão estratégica organizacional de uma cooperativa de crédito, por meio da utilização do Balanced Scorecard (BSC) e das perspectivas propostas por Kaplan e Norton (1997), visando identificar quais são os benefícios que a implantação do BSC pode oferecer para uma cooperativa de crédito. Caracteriza-se como um estudo de caso de cunho exploratório aplicado em uma cooperativa de crédito localizada no estado de Santa Catarina, com análise de dados qualitativa. Para a estruturação da proposta, consideraram-se as respostas dos gestores e colaboradores e as quatro perspectivas propostas pelo BSC, ponderando objetivos, metas e iniciativas para as perspectivas financeiras, de clientes, dos processos internos e de aprendizado e crescimento. Os resultados do estudo evidenciam que: (i) as fragilidades da instituição podem ser corrigidas a partir de metas e iniciativas, especialmente sob o enfoque dos clientes e da melhoria dos processos internos; (ii) a identificação de objetivos e metas permite a definição de iniciativas diretamente focadas na obtenção de melhores resultados para a entidade; e (iii) as estratégias da gestão da cooperativa de crédito estão refletidas em iniciativas que agregam e envolvem todos os colaboradores por meio da metodologia proposta pelo BSC.

Palavras-chave: Balanced Scorecard; BSC; Gestão estratégica.

\footnotetext{
1 Possui graduação em Ciências Contábeis pela Universidade Comunitária da Região de Chapecó, UNOCHAPECO, mestrado em Contabilidade pela Universidade Federal de Santa Catarina, UFSC e Doutorado em Contabilidade pela Universidade Federal de Santa Catarina, UFSC. Chapecó, SC-Brasil E-mail: silvanak@unochapeco.edu.br

2 Possui graduação em administração com ênfase em RH pela Celer Faculdades. Pós-graduada em Contabilidade e Gestão Empresarial pela Universidade Comunitária da Região de Chapecó, UNOCHAPECO. Chapecó, SC-Brasil Email:alyne_simionato@hotmail.com

3 Possui graduação em Administração pela Universidade Comunitária Regional de Chapecó, UNOCHAPECO e mestrado em Administração pela Universidade do Sul de Santa Catarina, UNISUL e doutorado em Administração pela Universidade Federal de Santa Catarina, UFSC. Chapecó, SC - Brasil. E-mail: cleunice@unochapeco.edu.br

4 Possui graduação em Ciências Contábeis pela Universidade do Vale do Itajaí, UNIVALI, mestrado em Engenharia de Produção pela Universidade Federal de Santa Catarina, UFSC e doutorado em Engenharia de Produção pela Universidade Federal de Santa Catarina, UFSC. Atualmente é professor adjunto da Universidade Federal de Santa Catarina e professor do Programa de Mestrado em Contabilidade (PPGC/UFSC). Florianópolis, SC- Brasil E-mail: smpetri@ gmail.com
} 


\section{INTRODUÇÃO}

$\mathrm{O}$ atual mercado competitivo e globalizado exige das empresas gerenciamento e controle, bem como o uso de informações que permitam avaliar o desempenho realizado. A análise das medidas de desempenho pode contribuir no acompanhamento dos fenômenos sociais, psicológicos e econômicos inerentes ao ambiente das organizações, que podem interferir em seu desempenho (BEUREN; SANTOS, 2013).

$\mathrm{O}$ crescimento econômico trouxe para as empresas o desafio de integrar os processos de gestão da qualidade, gestão ambiental e segurança, por meio de sistemas internos de gestão para atender às peculiaridades do mercado. Nesse sentido, há necessidade de melhorias também no gerenciamento dos processos produtivos, visando à redução dos custos e à adequação às características competitivas do mercado (FERNANDES et al., 2015).

De acordo com Kaplan e Norton (1997), um dos frequentes problemas do fracasso das organizações não está na elaboração das estratégias, mas sim na execução, especialmente das estratégias baseadas no conhecimento, as quais não são passíveis de medida, como, por exemplo, a motivação dos funcionários, o relacionamento com clientes e o uso de tecnologias.

Nessa perspectiva, o Balanced Scorecard (BSC) surge como uma ferramenta gerencial que possibilita a comunicação entre os ambientes internos, permitindo a interação com o ambiente estratégico, contribuindo para a consecução dos objetivos da organização e a operacionalização do discurso gerencial sobre objetivos, missão, valores e estratégias (COOPER; EZZAMEL, 2013).

O BSC é um instrumento gerencial que considera quatro perspectivas, conforme Kaplan e Norton (1997): a perspectiva financeira, de clientes, de processos internos e de aprendizado e crescimento. Prazeres, Lopes e Meira (2013) salientam que o BSC torna-se diferencial gerencial por facilitar a comunicação estratégica interna nas organizações, além de ampliar o potencial de geração de informações para o processo decisório. Nesse sentido, aparece a vantagem da utilização do BSC, por alinhar as ações organizacionais às estratégias, contribuindo com as necessidades dos gestores a partir das informações continuamente geradas.

A abordagem do BSC fornece uma prescrição sobre o que as empresas devem medir, mas o BSC não é simplesmente um sistema de medição, é na verdade um sistema de gestão que permite às organizações esclarecer sua visão e estratégia e traduzi-las em ações, contribuindo com o alinhamento dos objetivos em prol das iniciativas para alcançá-los (GRIGOROUDIS; ORFANOUDAKI; ZOPOUNIDIS, 2012).

Porto (2002) evidencia que o BSC oferece algumas vantagens também se utilizado como instrumento gerencial pelas entidades cooperativas, permitindo mensurar de modo amplo e detalhado o desempenho da empresa, proporcionando uma visão de que os departamentos são todos interligados e interdependentes, integrando a missão e a visão da cooperativa com as ações diárias do ambiente interno.

As cooperativas de crédito são sociedades de pessoas, e não de capital. Nelas, os cooperados participam com determinado valor (capital), com direito de participação nas decisões com poder de voto, através das assembleias. Os resultados de cada período são considerados sobras e são distribuídos entre os cooperados (RISSON; JUNIOR; PAULI, 2009). "Uma cooperativa pode ser constituída quando pessoas celebram contrato de sociedade cooperativa e se obrigam reciprocamente a contribuir com bens ou serviços para o exercício de uma atividade econômica, de proveito comum, sem objetivo de lucro." (CAMPOS, 2003, p. 51).

De acordo com Pinheiro (2008), desde a antiguidade vêm se experimentando formas de cooperação entre os homens. A primeira sociedade cooperativa surgiu em 1844, na Inglaterra, 
fundada por 28 tecelões. Em 1856, surgiu a primeira cooperativa de crédito na Alemanha. Essas cooperativas tinham como característica principal a distribuição das sobras de acordo com o capital dos associados. No Brasil, a primeira sociedade a ser considerada cooperativa foi a Sociedade Cooperativa Econômica dos Funcionários Públicos de Ouro Preto, em 1889, e a primeira cooperativa de crédito brasileira foi criada em 1902, em Nova Petrópolis/RS (PINHEIRO, 2008).

Nesse contexto, considerando a inserção das cooperativas de crédito e as vantagens propostas pela literatura na utilização do BSC como instrumento gerencial de apoio à comunicação entre os ambientes internos e o ambiente estratégico, o estudo sugere a implantação do BSC em uma cooperativa de crédito rural a partir das perspectivas do BSC e dos princípios cooperativos da entidade. Dessa forma, a problemática da pesquisa visa identificar: quais os benefícios que a implantação do BSC pode oferecer para uma cooperativa de crédito? O objetivo é elaborar um modelo por meio da utilização do BSC para a gestão estratégica organizacional de uma cooperativa de crédito, visando identificar quais são os benefícios que a implantação do BSC pode oferecer para uma cooperativa de crédito.

O estudo justifica-se pela relevância do alinhamento das estratégias com a missão e a visão das organizações no intuito de garantir a interação entre as estratégias e as iniciativas. Nesse sentido, a utilização do BSC permite a análise dos elementos conceituais propostos por Kaplan e Norton (1997) e das práticas de uma cooperativa de crédito. Ainda, a escassez de pesquisas direcionadas a essas entidades, especialmente quanto à implantação do BSC, também justifica a relevância do tema proposto.

\section{REVISÃO DA LITERATURA}

Nesta etapa, apresenta-se a abordagem e importância da implantação BSC, sob as quatro perspectivas de sua utilização, bem como estudos anteriores relacionados a essa temática.

\subsection{Balanced Scorecard}

As empresas enfrentam dificuldades em alinhar suas estratégias, geralmente porque separam o pensamento da ação, o que torna difícil a execução do planejado (HERRERO FILHO, 2005). Conforme Kaplan e Norton (1997), as empresas, no fim da década de 70, desenvolviam estratégias voltadas para os gestores da empresa e estas eram implantadas de forma centralizada. No entanto, as estratégias devem estar alinhadas internamente, envolvendo todos os setores, unidades e colaboradores.

Todas as organizações têm estratégias, sejam elas emergentes, sejam deliberadas, o que as difere é que as estratégias emergentes surgem no intuito de manter na medida do possível as estratégias deliberadas. Já as deliberadas justificam o planejamento estratégico, evidenciando o sentido das ações e a existência das empresas. No contexto das estratégias possíveis, deliberadas e emergentes, as decisões estratégicas indicam o que a organização pretende fazer e como o fará, mas também evidenciam o que a organização decide por não fazer ou executar, contemplando o posicionamento da marca ou da empresa frente ao mercado e cenário de atuação (ARAÚJO E SILVA; GONÇALVES, 2011).

As etapas do planejamento estratégico, na concepção de Hitt, Ireland e Hoskisson (2003), podem ser agrupadas em quatro conjuntos: (i) concepção estratégica (a missão e a visão são a razão de ser da instituição e dos negócios, ou seja, destaca-se como a empresa pretende ser no futuro); (ii) gestão do conhecimento estratégico (o diagnóstico interno e externo e a construção de cenários auxiliam no alinhamento das iniciativas); (iii) formulação estratégica (elaboração de ações por meio de planos operacionais e definição dos objetivos por ordem de urgência); e (iv) implementação da es- 
tratégia (envolvendo a estrutura e os controles organizacionais, governança corporativa e liderança).

Nesse sentido, o BSC possibilita aos gestores identificarem em quais atividades a empresa gera valor, sendo um sistema balanceado, no qual equilibra algumas variáveis que são mais importantes e estratégicas da empresa, como, por exemplo, objetivos de curto e longo prazo, ambiente interno e externo, parte financeira e intelectual etc. É um sistema de gestão que transforma estratégias em objetivos, medidas e metas, fazendo com que todos os setores da organização entendam as estratégias por meio das metas estabelecidas (HERRERO FILHO, 2005).

O BSC é definido por Kaplan e Norton (1997, p. 19) como "um instrumento que integra medidas financeiras derivadas das estratégias, sem menosprezar as medidas financeiras do desempenho passado". Silva e Callado (2013) enfatizam que o BSC é uma ferramenta gerencial voltada para mensuração do desempenho empresarial, através da organização de medidas financeiras e medidas não financeiras, as quais são alinhadas estrategicamente através de perspectivas, para a obtenção do objetivo empresarial a curto, médio e longo prazos.

De acordo com Kaplan e Norton (1997), o BSC possui como objetivos: (i) esclarecer e traduzir a visão e a estratégia da empresa; (ii) comunicar e associar objetivos, medidas e iniciativas estratégicas; e (iv) melhorar o feedback e o aprendizado estratégico das organizações.

Ainda, segundo Herrero Filho (2005), o BSC proporciona alguns benefícios, como (i) alinhamento da organização à estratégia; (ii) sinergia organizacional; (iii) construção de um sistema de gestão estratégica; (iv) articulação da estratégia ao planejamento e ao orçamento; (v) definição de metas estratégicas; (vi) prioridade a iniciativas estratégicas; e (vii) alinhamento dos indivíduos com a estratégia. O BSC é um método que busca explanar a visão e a missão da organização em um conjunto de providências de desempenho, procurando fazer de sua missão e estratégia uma fonte de motivação aos seus colaboradores, no intuito de atingir objetivos e diferenciais competitivos (PORTO, 2002; FERREIRA; LIMA JR., 2010).

A missão e a visão são os pontos de partida para a elaboração do BSC. Esses conceitos demonstram a preocupação dos executivos com as pessoas que trabalham na organização. As pessoas, no dia a dia, fazem-se algumas perguntas, como: que lugar ocupo nesta organização? O que devo fazer? Qual é minha possibilidade de crescimento? Entre outras. Nesse sentido, os colaboradores podem não encontrar respostas satisfatórias e isso ocorre geralmente porque os executivos e funcionários não têm clareza dos objetivos e não entendem qual é sua missão e visão. O BSC contribui na definição dos objetivos e possibilidades rumo aos objetivos da entidade (HERRERO FILHO, 2005).

Assim, o BSC é estruturado considerando quatro perspectivas, conforme Kaplan e Norton (1997):

1. Perspectiva financeira: identifica medidas e objetivos que promovam o retorno financeiro de curto a longo prazo da entidade, por meio de crescimento de receita ou redução de custos, buscando garantir a satisfação financeira com o empreendimento.

2. Perspectiva dos clientes: representa medidas de competitividade, contribuindo para ajustar os objetivos financeiros com os objetivos dos clientes por meio da satisfação, fidelização, captação e retenção de clientes.

3. Perspectiva dos processos internos: propõe medidas que orientam os processos internos para alcançar os objetivos dos clientes e investidores, a partir da melhoria dos pontos fracos ou críticos da organização.

4. Perspectiva do aprendizado e do crescimento: representa medidas que contribuem na melhoria da infraestrutura organizacional, visando contribuir com as demais perspectivas na obtenção de vantagens competitivas para a entidade. 
Essas quatro perspectivas apresentadas pelo BSC compreendem um modelo que visa contribuir com a comunicação constante dentro da organização, para, dessa forma, gerar mais eficácia na gestão da entidade, contribuindo para a melhoria de seus resultados (KAPLAN; NORTON, 1997). Destacam Najafi e Aryanezhad (2011) que o BSC converge aos objetivos de cada organização, segundo determinadas técnicas, além de medir a eficiência e determinar oportunidades a partir da produtividade das fontes existentes.

Segundo Porto (2002), o BSC, quando utilizado pelas entidades cooperativas, também oferece algumas vantagens, tais como a agregação de valor ao processo de gestão, permitindo a mensuração do desempenho de modo amplo e detalhado, proporcionando uma visão de que os departamentos são todos interligados e interdependentes, integrando a missão e a visão da cooperativa com as ações cotidianas e motivando a relação do ambiente interno com os desafios do ambiente externo.

De acordo com Najafi e Aryanezhad (2011), existem diferentes razões para medir a eficiência no setor bancário, tais como: (i) controle e supervisão de agências, que devem ser pesquisadas em relação aos padrões adequados; (ii) desempenho dos gerentes das agências bancárias, para recompensa por um sistema adequado de incentivos ou de punição, ou para criação de responsabilidades; (iii) medição do desempenho, para estabelecer normas de desempenho; e (iv) concurso entre os ramos ou departamentos, para a avaliação destes e para determinação dos poderes. A Figura 1 contempla um modelo de gestão das cooperativas proposto por Oliveira (2001).

Figura 1 - Modelo de gestão das cooperativas

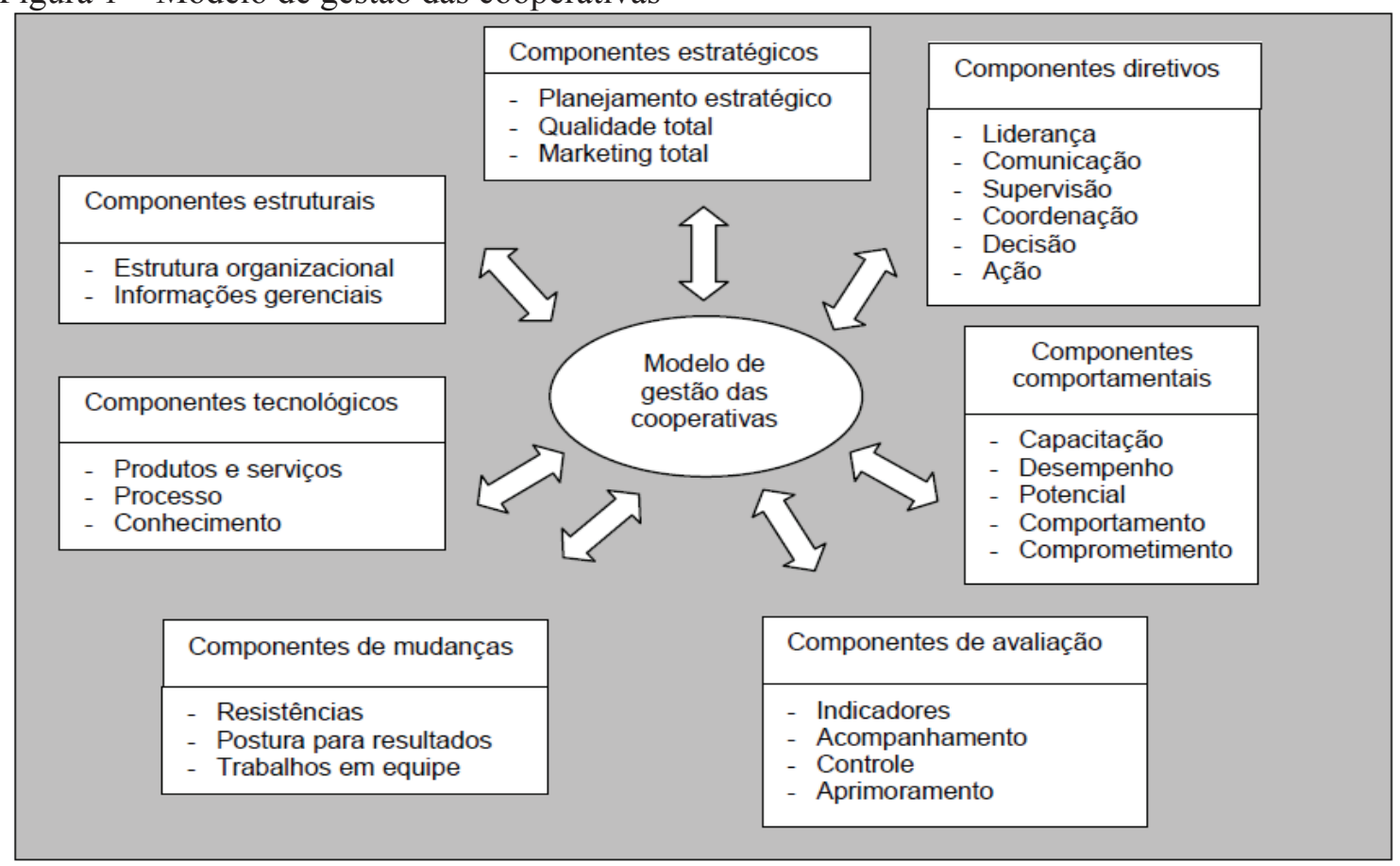

Fonte: Oliveira (2001, p. 58).

Observa-se que os componentes apresentados no modelo da Figura 1 são objetivos similares aos encontrados e adequados para outros tipos de empresas, tais como a captação de novos clientes, a retenção de clientes e a satisfação destes. Apenas no caso das cooperativas, observa-se a relação entre a entidade e seus cooperados, evidenciando a importância do BSC para alinhar as estratégias de gestão da cooperativa aos objetivos e iniciativas do ponto de vista operacional dos colaboradores. 
Destaca-se a importância da criação de conhecimento específico sobre as organizações visando ao aperfeiçoamento dos métodos de gestão em função das especificidades das entidades (GOMES; YASIN; LISBOA, 2004; NAYERI; MASHHADI; MOHAJERI, 2008). Nesse contexto, o planejamento estratégico permite o mapeamento de indicadores e medidas de desempenho, possibilitando aos gestores a compreensão das informações e a busca pela melhoria das práticas gerenciais (FRANCESCHINI; TURINA, 2013; KARATHANOS; KARATHANOS, 2005).

De forma geral, pode-se observar, no cenário econômico e mercadológico, a necessidade das organizações por modelos e informações que subsidiem o processo decisório, no intuito de aplicarem modelos gerenciais de apoio ao aperfeiçoamento do planejamento estratégico e da gestão empresarial (FRANCESCHINI; TURINA, 2013; CHEN; LEE; MO, 2012). Nesse sentido, o BSC torna-se instrumento de apoio à consecução das iniciativas e dos objetivos organizacionais, servindo de norteador ao processo de planejamento e gestão das atividades empresariais.

\subsection{Estudos anteriores relacionados à temática}

Estudos anteriores relacionados à temática estudada, conforme Prazeres, Lopes e Meira (2013), evidenciam que as pesquisas nacionais sobre o BSC emergem da necessidade de se identificar e consolidar tanto as aplicações do BSC quanto aos motivos que justificam a sua utilização pelas organizações.

No estudo de Porto (2002), o autor buscou inserir as perspectivas do BSC em uma cooperativa de crédito rural, de maneira a contribuir no processo de gestão da entidade. Para a inserção do modelo, foi utilizada como fonte de pesquisa uma cooperativa de crédito rural real, para conhecer e identificar as principais necessidades da cooperativa no segmento em que ela atua. Ao final da pesquisa, verificaram-se as principais vantagens de analisar a entidade, por meio do BSC, frente à forma atual de analisar seu desempenho. Contatou-se que não é possível gerenciar a cooperativa somente por indicadores financeiros e que a implantação do BSC mostrou-se fundamental para o gerenciamento das cooperativas de crédito rural, salvando suas peculiaridades.

O estudo de Ferreira e Lima Jr. (2010) teve como objetivo analisar o nível de satisfação dos associados e não associados na cooperativa Sicoob em Canoinhas, por meio da metodologia do BSC. A pesquisa classificou-se quanto aos objetivos como exploratória, quanto aos procedimentos como bibliográfica, estudo de caso e survey, e em relação ao problema como qualitativa e quantitativa. Por meio da aplicação do questionário que abordou propostas de valor sugeridas no BSC, foi possível medir o nível de satisfação dos clientes da cooperativa, comparando as informações e os objetivos específicos da entidade no segmento de clientes. Após a análise, foi possível a elaboração de um plano de melhorias que foi encaminhado à administração da cooperativa, podendo servir como suporte às decisões.

A pesquisa de Hubner et al. (2012) elabora um conjunto de fatores que permitem analisar a empresa sob as perspectivas do BSC, por meio da aplicação destas perspectivas em uma cooperativa de crédito. Trata-se de uma pesquisa descritiva do tipo levantamento e abordagem quantitativa do problema. A população da pesquisa abrange clientes, gerentes, contador, controller, administradores e colaboradores. Na perspectiva clientes, a amostra resultou em cinquenta respondentes, dez para a perspectiva financeira e quarenta respondentes para aprendizado. Os dados foram coletados por meio de um questionário e validados por meio de uma segunda rodada de questionamentos. Os autores concluem que a cooperativa necessita desenvolver esforços para atender aos clientes e colaboradores, para obter bons resultados nas atividades, como também para não avaliar somente a perspectiva financeira, mas também a qualidade dos produtos 
e serviços oferecidos, bem como a satisfação dos cooperados e clientes, no intuito de agregar, a longo prazo, novas iniciativas e garantir o desempenho sob o enfoque econômico-financeiro.

O estudo de Cortivo e Ceretta (2012) teve por objetivo criar um mapa estratégico para implementação de estratégias, utilizando-se da técnica do BSC em uma cooperativa de crédito, adaptando-o para a administração da entidade. A pesquisa caracterizou-se como estudo de caso, valendo-se de uma abordagem qualitativa, pesquisa documental e entrevista semiestruturada, aplicada na Cressol Itapejara. Como resultados, os autores elaboram um mapa estratégico, contendo os objetivos propostos pela entidade e os indicadores que possibilitam a identificação e o alcance dos objetivos, por meio das iniciativas, visando ao acompanhamento da evolução da cooperativa.

A pesquisa de Garcia et al. (2013) busca aplicar o BSC em uma cooperativa no município de Júlio de Castilhos/RS, visando principalmente observar a perspectiva dos clientes, de modo a avaliar a satisfação dos mesmos. O estudo foi realizado entre o período de janeiro de 2009 e novembro de 2010. Constatou-se que os clientes estão satisfeitos com a cooperativa e também que o fator preço não é o mais relevante.

O estudo de Soltanifar e Farhadib (2014) propõe um método para utilizar o BSC como uma ferramenta para a concepção de desempenho de índices de avaliação do setor bancário. Os autores realizam uma investigação empírica para medir a relação da eficiência de vários bancos localizados na província de Semnan/Iran; posteriormente, utilizam-se de testes estatísticos e da análise envoltória de dados (DEA), para evidenciar o desempenho de diferentes bancos.

O Quadro 1 apresenta os principais estudos similares a esta pesquisa, que aplicaram o BSC em entidades cooperadas, bem como os objetivos, principais objetivos estratégicos e principais indicadores dos objetivos estratégicos.

Quadro 1 - Estudos que aplicaram o BSC em cooperativas

\begin{tabular}{|c|c|c|}
\hline $\begin{array}{l}\text { Autores e ob- } \\
\text { jetivo da pes- } \\
\text { quisa }\end{array}$ & Principais objetivos estratégicos & $\begin{array}{l}\text { Principais indicadores dos objetivos estra- } \\
\text { tégicos }\end{array}$ \\
\hline $\begin{array}{l}\text { Porto (2002) } \\
\text { Propor um } \\
\text { modelo de } \\
\text { BSC para uma } \\
\text { cooperativa } \\
\text { de crédito. }\end{array}$ & $\begin{array}{l}\text { - Melhorar as sobras; } \\
\text { - Ampliar o mix de receitas; } \\
\text { - Aumentar a confiança dos cooperantes; } \\
\text { - Melhorar a satisfação dos cooperantes; } \\
\text { - Conhecer os segmentos de cooperantes; } \\
\text { - Desenvolver novos produtos; } \\
\text { - Atuar nos canais mais rentáveis; } \\
\text { - Reduzir falhas de serviço; } \\
\text { - Otimizar o atendimento ao cooperante; } \\
\text { - Fortalecer a estrutura de atendimento; } \\
\text { - Tornar o atual SI acessível e estratégico; } \\
\text { - Desenvolver habilidades estratégicas nos } \\
\text { funcionários; } \\
\text { - Alinhar as metas pessoais. }\end{array}$ & $\begin{array}{l}\text { - Retorno do capital empregado; } \\
\text { - Aumento das vendas nos segmentos; } \\
\text { - Redução dos custos por transação; } \\
\text { - Valor econômico agregado; } \\
\text { - Captação de cooperantes; } \\
\text { - Cooperantes desfiliados e inativos; } \\
\text { - Satisfação dos cooperantes; } \\
\text { - Lucratividade por segmentos-alvo; } \\
\text { - Receita gerada por novos produtos; } \\
\text { - Transações realizadas nos diversos canais; } \\
\text { - Tempo de atendimento das solicitações; } \\
\text { - Satisfação dos funcionários e rotatividade; } \\
\text { - Receita por remuneração de funcionário; } \\
\text { - Reconhecimento da visão da cooperativa. }\end{array}$ \\
\hline $\begin{array}{l}\text { Cortivo e Ce- } \\
\text { retta (2012) } \\
\text { Criar um } \\
\text { mapa estraté- } \\
\text { gico para im- } \\
\text { plementação } \\
\text { de estraté- } \\
\text { gias, utilizan- } \\
\text { do-se da téc- } \\
\text { nica do BSC. }\end{array}$ & $\begin{array}{l}\text { - Aumentar a receita; } \\
\text { - Obter sobras econômicas; } \\
\text { - Conquistar novos associados; } \\
\text { - Satisfazer o cooperado; } \\
\text { - Formar cadeia de valor; } \\
\text { - Estreitar os laços com o cooperado; } \\
\text { - Desenvolver novos produtos; } \\
\text { - Capacitar os funcionários; } \\
\text { - Desenvolver um sistema de informação } \\
\text { acessível e estratégico. }\end{array}$ & $\begin{array}{l}\text { - Percentual de transações com seus canais; } \\
\text { - Retorno sobre o capital empregado; } \\
\text { - Valor econômico agregado; } \\
\text { - Alavancagem das vendas; } \\
\text { - Redução dos custos; } \\
\text { - Rendimento por segmento; } \\
\text { - Percentual de receita gerada por produtos; } \\
\text { - Satisfação dos colaboradores; } \\
\text { - Rotatividade de funcionários; } \\
\text { - Produtividade dos colaboradores; } \\
\text { - Informação e qualidade das informações. }\end{array}$ \\
\hline
\end{tabular}




\begin{tabular}{|c|c|c|}
\hline $\begin{array}{l}\text { Hubner et al. } \\
(2012) \\
\text { Propor um } \\
\text { conjunto de } \\
\text { fatores que } \\
\text { podem re } \\
\text { constituir em } \\
\text { indicadores } \\
\text { de desem- } \\
\text { penho sob a } \\
\text { perspectiva } \\
\text { do BSC em } \\
\text { uma coope- } \\
\text { rativa de cré- } \\
\text { dito. }\end{array}$ & $\begin{array}{l}\text { - Remuneração; } \\
\text { - Agilidade no atendimento; } \\
\text { - Conhecimento do atendente; } \\
\text { - Horário diferenciado; } \\
\text { - Grau de conhecimento; } \\
\text { - Rapidez nas transações; } \\
\text { - Segurança e comodidade; } \\
\text { - Custos dos produtos/serviços; } \\
\text { - Diversidade de produtos/serviços; } \\
\text { - Inadimplência; } \\
\text { - Viabilidade de investimentos; } \\
\text { - Gerenciamento das despesas; } \\
\text { - Captação de investimentos; } \\
\text { - Taxas competitivas; } \\
\text { - Aumento de associados; } \\
\text { - Qualificação do quadro funcional. }\end{array}$ & $\begin{array}{l}\text { - Volume de vendas; } \\
\text { - Evolução do faturamento; } \\
\text { - Faturamento por produto; } \\
\text { - Evolução das vendas e serviços; } \\
\text { - Endividamento; } \\
\text { - Rentabilidade do capital próprio; } \\
\text { - Estimativa de evolução dos custos; } \\
\text { - Estimativa de diminuição dos custos; } \\
\text { - Investimento em marketing e publicidade; } \\
\text { - Investimento em novos produtos; } \\
\text { - Evolução na criação dos novos produtos; } \\
\text { - Evolução do patrimônio; } \\
\text { - Investimento em formação; } \\
\text { - Evolução do número de funcionários; } \\
\text { - Investimento na preservação do ambiente; } \\
\text { - Agilidade no atendimento. }\end{array}$ \\
\hline
\end{tabular}

Fonte: elaborado pelos autores com dados das pesquisas.

A partir das considerações quanto ao uso do BSC em diferentes tipos de organizações, observou-se que sua aplicação ou utilização, de modo geral, é indicada como benéfica para a gestão das organizações, contribuindo no alinhamento das estratégias organizacionais com os objetivos e metas a serem estabelecidas. Nesse sentido, o presente estudo busca utilizar-se do BSC como instrumento gerencial de apoio à comunicação em uma cooperativa de crédito rural, observando também os seus princípios cooperativos, visando identificar os benefícios que a implantação do BSC pode oferecer para a gestão organizacional.

\section{PROCEDIMENTOS METODOLÓGICOS}

Metodologicamente, a pesquisa se caracteriza como um estudo de caso, de cunho exploratório e com análise qualitativa dos dados. A pesquisa exploratória, segundo Raupp e Beuren (2004), deve ser aplicada quando não há muito conhecimento sobre o tema a ser abordado. 0 estudo de caso é caracterizado pelo estudo concentrado e aprofundado dos conhecimentos a respeito de um único caso em uma única empresa.

O estudo de caso aplicado é realizado em uma cooperativa de crédito rural com interação solidária localizada no município de Quilombo/SC. É uma cooperativa formada por agricultores familiares que se uniram para satisfazer interesses econômicos e sociais, constituindo uma cooperativa de crédito com o objetivo principal de conseguir o acesso ao crédito, visando beneficiar pequenos agricultores.

A análise de dados é predominantemente qualitativa. De acordo com Raupp e Beuren (2004), a pesquisa qualitativa concebe-se na análise mais profunda sobre o tema estudado, descrevendo a complexidade do ser humano, hábitos, atitudes, comportamento etc. Nesse sentido, para a efetividade do estudo, foram utilizados documentos internos da instituição e realizadas entrevistas com o conselho de administração da cooperativa, o qual é composto por um presidente, um vice-presidente, um secretário e mais quatro conselheiros. Aplicou-se ainda um questionário para coletar informações dos colaboradores da cooperativa.

Consideraram-se inicialmente a missão proposta pela cooperativa, qual seja, "fortalecer e estimular a interação solidária entre agricultores e cooperativas através do crédito orientado e da educação financeira com a construção do conhecimento, visando ao desenvolvimento sustentável"; e a visão, "ser referência no desenvolvimento local por meio do cooperativismo 
de crédito solidário, crescendo com foco na agricultura familiar, mantendo nossos diferenciais a partir do princípio da democracia, da profissionalização e do crédito orientado, atendendo a todas as necessidades financeiras e de serviços dos associados. Ter um modelo de gestão eficiente gerando inclusão financeira e resultado aos cooperados e às cooperativas de forma solidária e sustentável". Investigaram-se quais as perspectivas, do ponto de vista dos colaboradores, para estruturar as quatro perspectivas do modelo BSC. Identificou-se inicialmente o cargo ou função dos respondentes do questionário aplicado, conforme a Tabela 1.

Tabela 1 - Cargos dos respondentes

\begin{tabular}{c|c|c}
\hline Descrição da função & Frequência absoluta & Frequência relativa \\
\hline Presidente & 1 & $7,14 \%$ \\
\hline Vice-Presidente & 1 & $7,14 \%$ \\
\hline Conselheiros & 3 & $21,44 \%$ \\
\hline Caixa & 6 & $42,86 \%$ \\
\hline Assistente de Crédito & 1 & $7,14 \%$ \\
\hline Auxiliar Administrativo & 1 & $7,14 \%$ \\
\hline Técnico Agrícola & 1 & $7,14 \%$ \\
\hline Total & 14 & $100 \%$ \\
\hline
\end{tabular}

Fonte: dados da pesquisa.

A Tabela 1 apresenta as funções ou cargos ocupados pelos respondentes da pesquisa, correspondendo aos colaboradores que atuam na cooperativa de crédito em estudo. Quanto ao tempo de atuação na entidade pesquisada, identificaram-se os dados constantes na Tabela 2 .

Tabela 2 - Tempo de atuação dos respondentes na entidade

\begin{tabular}{c|c|c}
\hline Descrição & Frequência absoluta & Frequência relativa \\
\hline Até 1 ano & 3 & $21,43 \%$ \\
\hline De 1 a 3 anos & 2 & $14,28 \%$ \\
\hline De 3 a 5 anos & 5 & $35,72 \%$ \\
\hline De 5 a 8 anos & 3 & $21,43 \%$ \\
\hline De 8 a 10 anos & 1 & $7,14 \%$ \\
\hline Acima de 10 anos & 0 & 0 \\
\hline Total & 14 & $100 \%$ \\
\hline
\end{tabular}

Fonte: dados da pesquisa.

A Tabela 2 apresenta o tempo em que os colaboradores atuam na entidade. Como se pode perceber, cerca de $65 \%$ dos respondentes atuam na entidade há mais de três anos, e outros $21,43 \%$ estão na entidade há menos de um ano.

A coleta de dados considera o universo das pessoas que atuam na cooperativa, desde o presidente aos demais colaboradores. O questionário foi aplicado e respondido por todos os colaboradores que atuam na entidade, visando propor um modelo para a gestão estratégica organizacional, por meio da utilização do BSC e das perspectivas propostas pela metodologia do BSC (1997), visando identificar quais são os benefícios que a implantação dessa metodologia pode oferecer para uma cooperativa de crédito. 


\section{ANÁLISE DOS RESULTADOS E PROPOSTAS DE MELHORIAS}

Nesta seção, apresenta-se a análise dos dados da pesquisa aplicada junto aos colaboradores da cooperativa de crédito pesquisada, bem como uma proposta de melhoria a partir das perspectivas do BSC.

\subsection{Diagnóstico de caracterização da situação atual na perspectiva dos colaboradores}

Questionou-se os colaboradores sobre a sua compreensão da importância do planejamento e de seu acompanhamento para a atuação da cooperativa, conforme demonstra o Quadro 2.

Quadro 2 - A importância do planejamento na opinião dos colaboradores da entidade

\begin{tabular}{l}
\hline Sem planejamento, nenhuma empresa consegue alcançar sucesso e acompanhar o mercado em que está inserida. \\
\hline Ele é importante para que as ações sejam bem executadas e para evitar problemas futuros na cooperativa. \\
\hline $\begin{array}{l}\text { É ele que dá as diretrizes e contribui para a tomada de decisões, com ele a empresa sabe aonde quer } \\
\text { chegar e o que pretende alcançar. }\end{array}$ \\
\hline Ele dá um foco, determina estratégias e ações a curto e longo prazo. \\
\hline Com o planejamento, é possível detalhar: o que fazer, como fazer e quando fazer. \\
\hline
\end{tabular}
Fonte: dados da pesquisa.

Observa-se, no Quadro 2, pela transcrição das respostas dos respondentes, que estes possuem a percepção da importância do planejamento para o processo de gestão e definição dos objetivos da entidade. Questionou-se também os colaboradores quanto ao sistema utilizado pela Cresol, se atende à demanda e proporciona segurança nos processos de tomada de decisão. As respostas são apresentadas no Quadro 3.

Quadro 3 - Sistema utilizado pela cooperativa

A mudança do sistema tornou mais burocráticos os processos, tornando o atendimento mais lento. Por ser on-line, o sistema cai com frequência e prejudica o atendimento.

Possui mais campos para colocar informações relevantes.

Fonte: dados da pesquisa.

Observa-se, no Quadro 3, que os respondentes não estão totalmente satisfeitos com o sistema, porém os gestores relembramque este ainda se encontra em fase de adaptação, por ter sido substituído recentemente. O novo sistema visa proporcionar maior segurança aos processos, no entanto, por depender da internet, às vezes se torna mais lento.

Ainda, questionou-se os colaboradores da cooperativa de crédito sobre como a entidade deveria ser vista pelos associados para cumprir a sua missão e visão, conforme apresenta-se no Quadro 4.

Quadro 4 - Como a entidade deve ser vista pelos associados para alcançar a missão e a visão

Como um sistema que contribui no desenvolvimento do cooperativismo de crédito.

Como facilitadores no acesso ao crédito e na permanência no meio rural.

Como um sistema com linhas de crédito específicas para os agricultores, com apoio técnico e administrativo orientando os associados na tomada de decisões.

Como pessoas corretas, responsáveis e de confiança, preocupados em fornecer cada vez mais recursos para a melhoria da vida no campo, sempre dando oportunidade para que nossos associados participem da vida da cooperativa, aceitando opiniões e sugestões para melhorar cada vez mais.

Como uma cooperativa sustentável e de confiança, que visa principalmente beneficiar os agricultores. Fonte: dados da pesquisa. 
Observa-se, no Quadro 4, que os colaboradores possuem a percepção de que a cooperativa deve ser percebida pelos cooperados como um sistema confiável e seguro, comprometido com a qualidade de vida das pessoas do meio rural.

Nessa perspectiva, questionou-se os entrevistados sobre as mudanças que são necessárias na cooperativa para melhorar o atendimento aos sócios, conforme se pode observar no Quadro 5.

Quadro 5 - As mudanças necessárias para melhorar os processos de atendimento aos associados

Visitar e interagir com os associados para fortalecer o elo entre cooperativa, associados e colaboradores. Divulgar os produtos e serviços que são oferecidos pela cooperativa, bem como as vantagens de ser associado. Capacitar os colaboradores e o trabalho em equipe.

Implantar o autoatendimento.

Possuir um sistema mais ágil e avaliar melhor as condições do associado na hora de aprovar créditos. Fonte: dados da pesquisa.

Observam-se, no Quadro 5, sugestões que podem contribuir com melhorias no atendimento e satisfação dos colaboradores. Nesse sentido, ainda se indagou os colaboradores sobre as melhorias a serem realizadas pela entidade para preservar a capacidade de mudar e inovar. $\mathrm{O}$ Quadro 6 apresenta as contribuições.

Quadro 6 - Melhorias a serem realizadas pela entidade para preservar a capacidade de mudar e inovar

Continuar fazendo cursos de formação, aumentar a parceria entre as entidades e nunca esquecer o objetivo da cooperativa, quem constituiu o sistema, por que e por quem ele foi criado.

Visitar as propriedades, mantendo nossa forma de atendimento e taxas de juros.

Melhorar a infraestrutura do local para pessoas idosas e com deficiência física.

Investir mais em publicidade e estar em constante aperfeiçoamento, principalmente com as normativas do Banco Central.

Fonte: dados da pesquisa.

Observa-se novamente, no Quadro 6, que as sugestões e contribuições são possíveis e contribuem com a perspectiva dos clientes também. As propostas agregam benefícios que satisfazem também os usuários ou clientes da entidade.

Quanto aos objetivos financeiros para atingir e cumprir sua missão e visão e atender aos desejos dos associados, apresentam-se as sugestões no Quadro 7.

Quadro 7 - Objetivos financeiros que a instituição deve alcançar para cumprir a missão e a visão da cooperativa e atender às expectativas dos associados

Trabalhar a educação financeira com os associados com o objetivo de diminuir a inadimplência e garantir uma vida financeira saudável para a cooperativa, apresentando a cada final de exercício resultados positivos, que são distribuídos aos cooperados.

Acompanhar as inovações tecnológicas, porém continuar prestando atendimento humano, com espaço para dialogar com os associados.

Promover treinamento aos associados, orientar e acompanhar os projetos financiados, oferecer crédito na medida adequada e, com isso, tornar viáveis as propriedades rurais.

Continuar oferecendo linhas de crédito com juros menores aos agricultores.

Fonte: dados da pesquisa.

No Quadro 7, observa-se que, na opinião dos colaboradores, para atingir os objetivos financeiros, a entidade pode, a partir da capacitação dos colaboradores, melhorar o atendimento e o acesso às linhas de crédito rural aos cooperados. 
Para finalizar a coleta de dados, indagou-se os entrevistados sobre pontos fortes e fracos que a entidade possui frente às demais instituições financeiras, conforme se apresenta no Quadro 8.

Quadro 8 - Pontos fracos e pontos fortes da cooperativa na percepção dos colaboradores

\begin{tabular}{|l|l|}
\hline \multicolumn{1}{|c|}{ Pontos fracos } & \multicolumn{1}{|c|}{ Pontos fortes } \\
\hline Demora na liberação de repasse dos recursos. & $\begin{array}{l}\text { Taxas de juros diferenciadas para operações de crédito } \\
\text { rural. }\end{array}$ \\
\hline $\begin{array}{l}\text { Pouco contato e falta de visitas nas propriedades } \\
\text { rurais dos cooperados. }\end{array}$ & $\begin{array}{l}\text { Forma de atendimento com orientação técnica agríco- } \\
\text { la na hora de oferecer crédito, com assistência de um } \\
\text { técnico agrícola. }\end{array}$ \\
\hline $\begin{array}{l}\text { Dificuldade de manter os associados vinculados } \\
\text { apenas com a cooperativa de crédito, como úni- } \\
\text { ca instituição financeira. }\end{array}$ & $\begin{array}{l}\text { Gestão participativa e pelos próprios cooperados da } \\
\text { cooperativa, transparência nas decisões com participa- } \\
\text { ção direta dos cooperados. }\end{array}$ \\
\hline Não possuir autoatendimento. & $\begin{array}{l}\text { Conta-corrente sem pacote de tarifas, ou seja, inexis- } \\
\text { tência de custos de manutenção de contas. }\end{array}$ \\
\hline Dificuldade na venda de produtos e serviços. & $\begin{array}{l}\text { Trabalho voltado para a agricultura familiar, fortale- } \\
\text { cendo os objetivos da cooperativa e o vínculo com os } \\
\text { cooperados. }\end{array}$ \\
\hline
\end{tabular}

Fonte: dados da pesquisa.

Observa-se, no Quadro 8, que existem vários pontos a serem melhorados para garantir maior satisfação, principalmente por parte dos cooperados, bem como determinadas medidas a serem adotadas para diminuir algumas dificuldades, como, por exemplo, na venda de produtos e serviços. Em contraponto, observa-se que a cooperativa possui pontos fortes que podem ser explorados e fortalecidos pelos gestores no curto, médio e longo prazos.

\subsection{Propostas de melhorias a partir das perspectivas do BSC}

Neste tópico, propõe-se a utilização do BSC, considerando a análise das respostas do questionário aplicado. Sob as quatro perspectivas do BSC, pode-se identificar um conjunto de propostas e iniciativas que contribuam para a gestão da entidade pesquisada. No Quadro 9, observam-se os objetivos, indicadores, metas e iniciativas.

Quadro 9 - Propostas de melhorias a partir das perspectivas do BSC

\begin{tabular}{|c|c|c|c|c|c|}
\hline $\begin{array}{c}\text { Perspec- } \\
\text { tiva }\end{array}$ & Objetivos & Indicadores & $\begin{array}{c}\text { Situação } \\
\text { atual }\end{array}$ & Metas & Iniciativas \\
\hline \multirow[t]{3}{*}{ Clientes } & $\begin{array}{l}\text { Aumento do } \\
\text { número de coo- } \\
\text { perados. }\end{array}$ & $\begin{array}{l}\text { Crescimento } \\
\text { anual do nú- } \\
\text { mero de coo- } \\
\text { perados da co- } \\
\text { operativa. }\end{array}$ & 1.645 & $\begin{array}{c}\text { Apresentar cresci- } \\
\text { mento de } 10 \% \text { da } \\
\text { carteira de coope- } \\
\text { rados. }\end{array}$ & $\begin{array}{l}\text { - Conquistar clientes que usam } \\
\text { a cooperativa para serviços; } \\
\text { - Ter um colaborador responsá- } \\
\text { vel pelas visitas de campo. }\end{array}$ \\
\hline & $\begin{array}{l}\text { Fidelização dos } \\
\text { cooperados. }\end{array}$ & $\begin{array}{l}\text { Número de co- } \\
\text { operados usu- } \\
\text { ários dos servi- } \\
\text { ços ativos. }\end{array}$ & Verificando & $\begin{array}{l}\text { Manter ativo o } \\
\text { atual número de } \\
\text { cooperados. }\end{array}$ & \multirow{2}{*}{$\begin{array}{l}\text { - Dividir a carteira de clientes } \\
\text { para garantir o acompanha- } \\
\text { mento de todos os cooperados; } \\
\text { - Realizar visitas de campo e } \\
\text { aproximar o relacionamento. } \\
\text { - Adequar entradas, local de es- } \\
\text { pera e sanitários; } \\
\text { - Orientar a preferência no } \\
\text { e atendimento; } \\
\text { - Reformar o local para atender } \\
\text { às condições de acessibilidade. }\end{array}$} \\
\hline & $\begin{array}{l}\text { Melhoria da in- } \\
\text { fraestrutura de } \\
\text { atendimento. }\end{array}$ & Acessibilidade & $\begin{array}{l}\text { Inadequa- } \\
\qquad \text { da }\end{array}$ & $\begin{array}{l}\text { Permitir acesso } \\
\text { facilitado para por- } \\
\text { tadores de neces- } \\
\text { sidades especiais e } \\
\text { da terceira idade. }\end{array}$ & \\
\hline
\end{tabular}




\begin{tabular}{|c|c|c|c|c|c|}
\hline $\begin{array}{c}\text { Apren- } \\
\text { dizado e } \\
\text { Cresci- } \\
\text { mento }\end{array}$ & $\begin{array}{l}\text { Agilidade no } \\
\text { atendimento. }\end{array}$ & $\begin{array}{l}\text { Tempo médio } \\
\text { de espera para } \\
\text { atendimento. }\end{array}$ & Verificando & $\begin{array}{c}\text { Garantir que o } \\
\text { tempo de espera } \\
\text { seja de, no máxi- } \\
\text { mo, } 15 \text { minutos } \\
\text { na fila de atendi- } \\
\text { mento. } \\
\end{array}$ & $\begin{array}{l}\text { - Adquirir máquina para auto- } \\
\text { atendimento e disponibilizar o } \\
\text { site para a realização de transa- } \\
\text { ções; } \\
\text { - Ter atendentes que orientam } \\
\text { as operações aos clientes, com } \\
\text { preferência aos cooperados. }\end{array}$ \\
\hline \multirow[t]{2}{*}{$\begin{array}{c}\text { Proces- } \\
\text { sos Inter- } \\
\text { nos }\end{array}$} & $\begin{array}{l}\text { Capacitação dos } \\
\text { colaboradores e } \\
\text { cooperados. }\end{array}$ & $\begin{array}{l}\text { - Participação } \\
\text { dos colabora- } \\
\text { dores em cur- } \\
\text { sos de capaci- } \\
\text { tação e atuali- } \\
\text { zação; } \\
\text { - Participação } \\
\text { dos coopera- } \\
\text { dos em cursos, } \\
\text { palestras ou } \\
\text { eventos. }\end{array}$ & 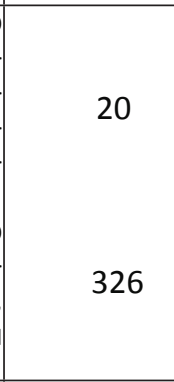 & $\begin{array}{l}\text { - Participar de, no } \\
\text { mínimo, um curso } \\
\text { por semestre por } \\
\text { colaborador; } \\
\text { - Promover a par- } \\
\text { ticipação de } 85 \% \\
\text { dos cooperados } \\
\text { em cursos, pales- } \\
\text { tras ou eventos } \\
\text { corporativos. }\end{array}$ & $\begin{array}{l}\text { - Organizar cursos ou capaci- } \\
\text { tações para os colaboradores, } \\
\text { que atendam às necessidades } \\
\text { do ambiente da cooperativa; } \\
\text { - Organizar eventos corpora- } \\
\text { tivos para mobilizar a partici- } \\
\text { pação dos cooperados e in- } \\
\text { centivar a participação destes, } \\
\text { inclusive nas assembleias da } \\
\text { entidade. }\end{array}$ \\
\hline & $\begin{array}{c}\text { Conhecimento } \\
\text { das vantagens do } \\
\text { sistema coope- } \\
\text { rativo. }\end{array}$ & $\begin{array}{l}\text { Ca p a cit a çã o } \\
\text { dos colabora- } \\
\text { dores quanto } \\
\text { às vantagens } \\
\text { da inserção no } \\
\text { sistema coope- } \\
\text { rativo. }\end{array}$ & 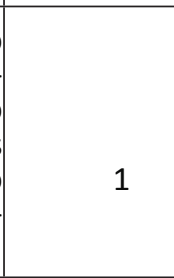 & \begin{tabular}{|} 
Promover capa- \\
citação trimestral \\
para $100 \%$ dos \\
colaboradores que \\
atendem ao pú- \\
blico.
\end{tabular} & $\begin{array}{l}\text { - Promover oficinas e/ou trei- } \\
\text { namentos sobre o sistema } \\
\text { cooperativo a cada trimestre, } \\
\text { esclarecendo as vantagens do } \\
\text { associativismo; } \\
\text { - Promover oficinas e/ou trei- } \\
\text { namentos sobre os produtos e } \\
\text { servicos da cooperativa. }\end{array}$ \\
\hline \multirow[t]{2}{*}{ Finanças } & $\begin{array}{l}\text { Aumento das } \\
\text { sobras em cada } \\
\text { exercício. }\end{array}$ & $\begin{array}{l}\text { Garantia de so- } \\
\text { bras aos coope- } \\
\text { rados em cada } \\
\text { exercício social. }\end{array}$ & $\begin{array}{l}8,40 \% \\
(2013)\end{array}$ & $\begin{array}{l}\text { Promover incre- } \\
\text { mento de } 10 \% \text { ao } \\
\text { ano das sobras. }\end{array}$ & $\begin{array}{l}\text { - Aumentar a captação de re- } \\
\text { cursos dos cooperados e dos } \\
\text { serviços prestados (financia- } \\
\text { mentos, poupança, seguro } \\
\text { etc.), oferecendo aos coopera- } \\
\text { dos os servicos. }\end{array}$ \\
\hline & $\begin{array}{c}\text { Incremento de } \\
\text { serviços oferta- } \\
\text { dos aos coope- } \\
\text { rados. }\end{array}$ & $\begin{array}{l}\text { Aumento dos } \\
\text { serviços oferta- } \\
\text { dos por coope- } \\
\text { rado. }\end{array}$ & Verificando & $\begin{array}{c}\text { Garantir, no mí- } \\
\text { nimo, um serviço } \\
\text { adicional por coo- } \\
\text { perado, por conta- } \\
\text { corrente. }\end{array}$ & $\begin{array}{l}\text { - Informar as possibilidades de } \\
\text { serviços ofertados pela entida- } \\
\text { de; } \\
\text { - Agregar recursos por meio de } \\
\text { campanhas de captação de ser- } \\
\text { viços. }\end{array}$ \\
\hline
\end{tabular}

Fonte: dados da pesquisa.

Observa-se, no Quadro 9, a proposta de objetivos, metas, indicadores e iniciativas para alinhar o motivo da existência da cooperativa de crédito às suas estratégias de gestão a partir das quatro perspectivas propostas pelo BSC. As estratégias e os objetivos propostos, bem como tais metas e iniciativas são propostos a partir do questionamento e das sugestões ponderadas pelos colaboradores.

Observa-se que a missão da cooperativa de "fortalecer e estimular a interação solidária entre agricultores e cooperativas através do crédito orientado e da educação financeira com a construção do conhecimento, visando ao desenvolvimento sustentável", é estimulada quando ocorre a oferta de serviços e o apoio aos agricultores da região, por meio da oferta de serviços e da cooperação com a cooperativa. Nesse sentido, entende-se que é primordial que os colaboradores conheçam e possam enfatizar tais vantagens aos cooperados e futuros associados, visando tornar-se "referência no desenvolvimento local por meio do cooperativismo de crédito solidário, crescendo com foco na agricultura familiar, mantendo os diferenciais a partir do princípio da democracia, da profissionalização e do crédito orientado, atendendo às necessidades financeiras e de serviços dos associados", como sua visão propõe.

Dessa forma, as perspectivas financeiras e de clientes poderão de fato estabelecer um modelo de gestão eficiente, gerando inclusão financeira e resultado aos cooperados e à cooperativa de forma solidária e sustentável. 
Observou-se que, na perspectiva de processos internos, uma alternativa para minimizar o tempo de atendimento e as filas, que prejudicam o relacionamento com clientes, seria ajustar o software para disponibilizar operações, especialmente consultas e pagamentos pela internet, bem como adquirir e dispor de máquinas de autoatendimento. Os resultados dessas ações refletem na agilidade de atendimento e até na diferenciação do horário de atendimento. Ainda, outra medida a ser tomada nessa perspectiva é adaptar a infraestrutura do local para idosos e pessoas com deficiência física, a fim de proporcionar um ambiente aconchegante e de fácil acesso principalmente a essas pessoas, além de atender às normativas legais de acessibilidade.

Sob o enfoque dos processos internos, salienta-se ainda que o conhecimento sobre as vantagens e a proposta do sistema cooperativo, as políticas do sistema e o motivo de sua existência devem ser conhecidos e percebidos pelos colaboradores e cooperados. Nesse sentido, o ideal é promover capacitação a cada trimestre com os novos sócios do período, expondo as vantagens da cooperativa, como é seu funcionamento, horários, direitos e deveres dos associados, bem como capacitando os colaboradores.

Em uma sociedade cooperativa, todos os envolvidos esperam obter sobras ao final de cada exercício, afinal esse é um dos grandes diferenciais que as cooperativas de crédito possuem frente às demais instituições financeiras: cada cooperado recebe um percentual sobre a movimentação de sua conta-corrente, conta-aplicação e conta-empréstimos, ou seja, quanto mais o associado movimentar na cooperativa, maior será o valor que receberá em cotas capital. De acordo com o questionário aplicado para alcançar a missão e a visão da cooperativa, os cooperados devem perceber a entidade como uma instituição confiável, que apresenta resultados positivos aos agricultores, que incentiva a permanência das pessoas no meio rural e que promove os princípios e valores que motivaram a sua constituição.

Nesse sentido, os resultados contribuem com as considerações de Prazeres, Lopes e Meira (2013), que evidenciam que o BSC envolve aspectos multidisciplinares e pode ser utilizado nas mais diversas áreas do conhecimento aplicado à gestão organizacional. Da mesma forma, corroboram a análise de Da Silva Ulyssea et al. (2013), quando salientam que, para se conseguir alcançar uma estratégia vinculada à medida, é necessária a elaboração de iniciativas, por meio de indicadores de resultados. Os resultados vão ao encontro do modelo de Hubner et al. (2012) e Cortivo e Ceretta (2012) quando se observa que o BSC permite o alinhamento entre objetivos e ações ou iniciativas, facilitando o processo de comunicação para as entidades cooperativas de crédito.

De modo geral, os resultados do estudo evidenciam que: (i) as fragilidades da instituição podem ser corrigidas a partir de metas e iniciativas especialmente sob o enfoque dos clientes e da melhoria dos processos internos; (ii) a identificação de objetivos e metas permite a definição de iniciativas diretamente focadas na obtenção de melhores resultados para a entidade; e (iii) as estratégias da gestão da cooperativa de crédito estão refletidas em iniciativas que agregam e envolvem todos os colaboradores por meio da metodologia proposta pelo BSC considerando as quatro perspectivas de sua estruturação.

Entende-se que o BSC pode contribuir com o alinhamento das estratégias da cooperativa, a partir das metas e iniciativas propostas, considerando-se que, até então, a cooperativa não possuía regime de metas, dificultando o planejamento com as ações. Por isso, a partir das necessidades percebidas após a pesquisa aplicada e das perspectivas do BSC, sugere-se o desenvolvimento e acompanhamento das iniciativas propostas em cada uma das perspectivas do BSC, visando agregar vantagens e melhores resultados, a longo prazo, para a gestão estratégica e competitividade da cooperativa de crédito em estudo. 


\subsection{Análises dos resultados}

Observando a proposta de objetivos, metas, indicadores e iniciativas para alinhar o motivo da existência da cooperativa de crédito às suas estratégias de gestão a partir das quatro perspectivas propostas pelo BSC, apresentadas no Quadro 9, e relacionando-as aos objetivos e indicadores propostos pelos estudos anteriores apresentados no Quadro 1, ponderam-se as seguintes particularidades do atual modelo proposto:

1. objetivos e indicadores reduzidos para o processo inicial da adoção do BSC, visando alinhar as estratégias iniciais com as necessidades imediatas da entidade;

2. identificação das iniciativas que possam levar a entidade à obtenção das metas e objetivos estabelecidos pelos gestores, de forma a propiciar o alinhamento dessas com as ações, ou seja, gestores e colaboradores têm os mesmos objetivos a serem alcançados;

3. linguagem e comunicação entre os setores frente às metas da entidade estão ponderadas e permitem que os gestores as utilizem para motivar a equipe e medir o desempenho individual por colaborador;

4. identificação da situação atual permite que a equipe conheça e observe como tais iniciativas contribuem para que a entidade alcance os resultados desejados, motivando os colaboradores na identificação de novas iniciativas e permitindo que o BSC seja reconstruído e ajustado permanentemente.

A partir dos avanços e desse alinhamento inicial entre estratégias e iniciativas, a entidade poderá inserir novos objetivos, tais como os propostos por Hubner et al. (2012) e Cortivo e Ceretta (2012), além daqueles que poderão ser percebidos no próprio ambiente interno pelos gestores e colaboradores.

\section{CONCLUSÕES}

Este estudo propõe um modelo para a gestão estratégica organizacional de uma cooperativa de crédito por meio da utilização das quatro perspectivas propostas pelo BSC, visando identificar quais são os benefícios que a implantação dessa metodologia pode oferecer para uma cooperativa de crédito. Para a estruturação da proposta, foram consideradas as respostas dos gestores e colaboradores, ponderando objetivos, metas e iniciativas para as perspectivas financeiras, de clientes, dos processos internos e de aprendizado e crescimento.

Observou-se, a partir do estudo desenvolvido, que o BSC é uma ferramenta que permite envolver os vários setores da empresa em busca de aprimorá-los e relacionar as estratégias com iniciativas concretas, visando torná-la mais competitiva, permitindo que todos os envolvidos conheçam os objetivos e as decisões, que são orientadas com maior veracidade e eficácia e justificadas pelas metas a serem alcançadas.

Considerando a inserção das cooperativas de crédito e as vantagens propostas pela literatura para a utilização do BSC como instrumento gerencial de apoio à comunicação entre os ambientes internos e o ambiente estratégico, o estudo sugere a implantação do BSC em uma cooperativa de crédito rural a partir das quatro perspectivas do modelo BSC. Dessa forma, respondendo à problemática da pesquisa, observou-se que as principais necessidades para a gestão da entidade alinhar o motivo da existência da cooperativa de crédito com as estratégias da gestão 
a partir das perspectivas do BSC se referem a: conquistar novos clientes que usam a cooperativa para serviços; realizar visitas de campo; adequar instalações físicas de acessibilidade e de autoatendimento; organizar cursos ou capacitações para os colaboradores e cooperados; e aumentar a captação de recursos dos cooperados e dos serviços prestados.

Nesse sentido, os resultados evidenciam a importância da utilização do BSC para a gestão estratégica organizacional dessa cooperativa de crédito, permitindo a identificação de objetivos e iniciativas que contribuem com o alinhamento das estratégias da gestão e de sua missão e visão. Ainda, observou-se que a utilização do BSC permite a análise dos elementos conceituais propostos por Kaplan e Norton (1997) e das práticas organizacionais, partindo da realidade de cada organização. Nesse sentido, os resultados do estudo permitem observar que a utilização do BSC contribui na identificação das estratégias e na definição de objetivos e metas a serem alcançadas, bem como traduz tais objetivos em iniciativas, facilitando o processo decisório e a gestão dos processos internos.

Como sugestão e contribuição para futuras pesquisas, sugere-se o acompanhamento e análise da implantação e efetividade dos resultados alcançados a partir da utilização do BSC pelos gestores das entidades, em novas condições e realidades empresariais.

Dessa forma, entende-se que o estudo agrega novos objetivos, metas e indicadores estratégicos sob as quatro perspectivas do BSC, evidenciando que, como ferramenta gerencial, o BSC é flexível e ajustável ao modelo de gestão de cada entidade e busca adequar-se a essa realidade, contribuindo como proposta para a adoção do BSC em cooperativas de crédito ou instituições de crédito de natureza similar.

\section{REFERÊNCIAS}

ARAÚJO ESILVA, F.; GONÇALVES, C. A. O processo de formulação e implementação de planejamento estratégico em instituições do setor público. Revista de Administração da UFSM, v. 4, n. 3, p. 458476, 2011.

BEUREN, I. M.; SANTOS, A. C. dos. Balanced scorecard: fins de sua utilização por gestores. Revista Economia e Gestão, v. 13, n. 33, 2013.

CAMPOS, A. Complexo normativo das cooperativas de crédito. Brasília: OAB Editora, 2003.

CHEN, Y.; LEE, S.; MO, H. Innovative operation in a private University of Technology an application of strategy map on Balanced Scorecard. International Journal of Asian Social Science, v. 2, n. 11, p. 1.877-1.891, 2012.

CORTIVO, B.; CERETTA, G. F. Um modelo de alinhamento para implementação de estratégias utilizando-se do Balanced Scorecard. Curso em cooperativismo solidário da UNIOESTE. Francisco Beltrão, 2012. Disponível em: <http://www.cresol.com.br/site/upload/downloads/119.pdf>. Acesso: 2 fev. 2014.

COOPER, D. J.; EZZAMEL, M. Globalization discourses and performance measurement systems in a multinational firm. Accounting, Organizations and Society, v. 38, p. 288-313, 2013.

DA SILVA ULYSSEA, D. et al. Balanced Scorecard em uma instituição de ensino superior: uma proposta de modelo para gestão estratégica. Revista Catarinense da Ciência Contábil, v. 12, n. 35, p. 28-47, 2013. 
FEREIRA, V.; LIMA JR., R. Balanced Scorecard: uma abordagem voltada ao cliente na Cooperativa de Livre Admissão de Associados - Sicoob Canoinhas/SC. Revista Catarinense da Ciência Contábil - CRC/SC, v. 9, n. 26, p. 9-25, 2010.

FERNANDES, J. L. S. et al. Etapas necessárias para a implantação de um sistema de gestão integrado. Revista de Administração da UFSM, v. 8, n. 1, p. 60-72, 2015.

FRANCESCHINI, F.; TURINA, E. Quality improvement and redesign of performance measurement systems: an application to the academic field. Quality \& Quantity, v. 47, n. 1, p. 465-483, 2013.

GARCIA, F. T. et al. Um estudo sobre indicadores de desempenho na perspectiva cliente a partir do balanced scorecard. Revista de Administração da UNIMEP, v. 11, n. 1, 2013.

GRIGOROUDIS, E.; ORFANOUDAKI, E.; ZOPOUNIDIS, C. Strategic performance measurement in a healthcare organization: a multiple criteria approach based on balanced scorecard. Omega, v. 40, n. 1, p. 104-119, 2012.

GOMES, C. F.; YASIN, M. M.; LISBOA, J. V. A literature review of manufacturing performance measures and measurement in an organizational context: a framework and direction for future research. Journal of Manufacturing Technology Management, v. 15, n. 6, p. 511-530, 2004.

HERRERO FILHO, E. Balanced scorecard e a gestão estratégica: uma abordagem prática. 4. ed. Rio de Janeiro: Elsevier, 2005.

HITT, M. A.; IRELAND, R. D.; HOSKISSON, R. E. Administração estratégica. São Paulo: Bookman, 2003.

HUBNER, B. T. et al. Proposta de indicadores de performance sob a perspectiva do Balanced Scorecard: o caso de uma cooperativa de crédito. Revista Catarinense da Ciência Contábil - CRC/ SC, v. 11, n. 31, p. 9-32, 2012.

KAPLAN, R. S.; NORTON, D. P. A estratégia em ação: balanced scorecard. 22. ed. Rio de Janeiro: Elsevier, 1997.

KARATHANOS, D.; KARATHANOS, P. Applying the balanced scorecard to education. Journal of Education for Business, v. 80, p. 222-231, 2005.

NAJAFI, E.; ARYANEZHAD, M. A BSC-DEA approach to measure the relative efficiency of service industry: A case study of banking sector. International Journal of Industrial Engineering Computations, v. 2, n. 2, p. 273-282, 2011.

NAYERI, M. D.; MASHHADI, M. M.; MOHAJERI, K. Universities strategic evaluation using balanced scorecard. World Academy of Science, Engineering and Technology, v. 37, p. 332-337, 2008.

OLIVEIRA, D. de P. R. de. Manual de gestão das cooperativas: uma abordagem prática. São Paulo: Atlas, 2001.

PINHEIRO, M. A. H. Cooperativas de crédito: história da evolução normativa no Brasil. 2008. Disponível em: <http://www.bcb.gov.br/htms/public/microcredito/livro_cooperativas_credito. pdf $>$. Acesso em: 17 ago. 2013. 
PORTO, W. S. Avaliação de desempenho de cooperativas de crédito rural baseada no uso do Balanced Scorecard: uma proposta de modelo. 2002. 80 f. Dissertação (Mestrado em Engenharia de Produção)-Universidade Federal de Santa Catarina, Florianópolis, 2002.

PRAZERES, R. V. dos; LOPES, L. da C.; MEIRA, J. M. Balanced Scorecard (BSC): uma análise do perfil de suas aplicações nos anais do ANPCONT, ENANPAD e USP. Revista de Contabilidade da UFBA, Salvador, BA, v. 7, n. 2, p. 52-65, 2013.

RAUPP, F. M.; BEUREN, I. M. Metodologia da pesquisa aplicável às ciências sociais. In: BEUREN, I. M. (Org.). Como elaborar trabalhos monográficos em contabilidade: teoria e prática. São Paulo: Atlas, 2004. p. 76-96.

RISSON, C.; JUNIOR, E. G.; PAULI, J.. Desenvolvimento, democracia e gestão do crédito: a agricultura familiar em debate. Passo Fundo: IMED, 2009.

SILVA, M. D. de O. P.; CALLADO, A. A. C. Análise de Modelos de Balanced Scorecard elaborados a partir da Ótica da Sustentabilidade através do uso da Matriz SWOT. Revista de Administração, contabilidade e sustentabilidade - Reunir, v. 3, n. 4, p. 87-103, 2013.

SOLTANIFAR, M., FARHADI, F. An application of data envelopment analysis for measuring the relative efficiency in banking industry. Management Science Letters, v. 4, n. 5, p. 1.021-1.026, 2014. 